\title{
GLOBAL ENERGY STRATEGIES TO CONTROL FUTURE CARBON DIOXIDE EMISSIONS
}

Yuri Sinyak

International Institute for Applied Systems Analysis

Laxenburg, Austria

Koji Nagano

Central Research Institute of Electric Power Industry, Otemachi Building, 1-61-Otemachi, Tokyo 100, Japan

RR-94-7

July 1994

Reprinted from Energy, Vol. 19, No. 2, pp. 227-236, 1994.

INTERNATIONAL INSTITUTE FOR APPLIED SYSTEMS ANALYSIS

Laxenburg, Austria 
Research Reports, which record research conducted at IIASA, are independently reviewed before publication. Views or opinions expressed herein do not necessarily represent those of the Institute, its National Member Organizations, or other organizations supporting the work.

Reprinted with permission from Energy Vol. 19, No. 2, pp. 227-236, 1994.

Copyright (C)1994 Elsevier Science Ltd.

All rights reserved. No part of this publication may be reproduced or transmitted in any form or by any means, electronic or mechanical, including photocopy, recording, or any information storage or retrieval system, without permission in writing from the copyright holder.

Printed by Novographic, Vienna, Austria. 


\section{Preface}

This report summarizes the findings of a joint study by the International Institute for Applied Systems Analysis (IIASA) and the Central Research Institute of the Electric Power Industry (CRIEPI) that was conducted from 1990 to 1992 . The study focused on possible global energy strategies to reduce future carbon dioxide emissions and involved the development of an analytical framework to evaluate long-term energy development strategies and to help develop alternative global and regional energy and carbon dioxide emissions scenarios.

Two simulation models were linked in the analytical framework: the energy demand model, MEDEE-2, and the energy supply model, LEAP. Numerous scenario assumptions, e.g., the rates of future population and economic growth, were used to derive the final energy requirements in the demand model. These were then used as basic inputs for the energy supply model in order to determine primary energy consumption and emissions of carbon dioxide.

Two basic scenarios were developed; each scenario consisted of three change cases so that a total of six scenarios was elaborated. One of the two basic scenarios was a reference case and the other assumed higher rates of efficiency improvements. In the reference case, the energy efficiency improvement rates were assumed to be the same as those observed since the 1970s. The scenario, with accelerated efficiency improvement, also included reduced energy requirements as a result of changes in social behavior with modest changes in the primary energy mix.

The scenarios covered a wide range of possible future carbon dioxide emissions from almost a doubling of carbon dioxide emissions by the year 2050 (in the reference case with a nuclear moratorium) to a 60 percent reduction of current emissions levels (in the accelerated abatement case). The authors argue that integrated assessments of measures to prevent, mitigate or adapt to climate change will be especially important in identifying acceptable global response strategies given the potential alternative futures described by the scenarios. Currently, a number of research efforts at IIASA 
are being linked to an integrated assessment framework. IIASA, together with Stanford University, is the co-organizer of the Energy Modeling Forum 14 which is exclusively devoted to integrated assessment. The joint IIASA and CRIEPI study presented in this report is one of a number of studies that identify integrated assessment as a promising direction for future research.

Nebojša Nakićenović

Leader

Environmentally Compatible Energy Strategies Project 


\title{
GLOBAL ENERGY STRATEGIES TO CONTROL FUTURE CARBON DIOXIDE EMISSIONS
}

\author{
YURI SinYaK†‡ and KoJI NaGano \\ $\dagger$ International Institute for Applied Systems Analysis, IIASA, A-2361 Laxenburg, Austria and \\ $\$$ Central Research Institute of Electric Power Industry, CRIEPI, Otemachi Building, 1-6-1 Otemachi, \\ Chiyoda-Ku, Tokyo 100, Japan
}

(Received 8 February 1993; received for publication 21 July 1993)

\begin{abstract}
We analyse long-term energy prospects from the point of view of future carbon dioxide emissions and constraints imposed by possible changes in the global climate. The approach is based on scenario simulations of technical, economic, social, and cultural changes which determine future energy use and their environmental impacts to the middle of the next century. For this purpose, two scenarios have been formulated: one with changes in society, the economic system, and the energy sector that follow the dynamic-as-usual pattern and the other with enhanced energy-efficiency improvements and conservation efforts. For each scenario, three different cases have been investigated reflecting possible situations on the energy supply-side. The consequences of various policy options in energy supply and demand have been evaluated to understand the efficacy of different measures in approaching a global greenhouse-gas-abatement energy policy.
\end{abstract}

\section{INTRODUCTION}

The evolution of natural systems that feed and sustain human populations, and indeed the evolution of modern society, has occurred in the context of a moderate and stable climate. However, the atmospheric concentration of carbon dioxide $\left(\mathrm{CO}_{2}\right)$ has been increasing since the industrial revolution and is now considered a major cause of possible global warming. The energy system is the first area to work on to prevent global warming because two-thirds of the carbon released into the atmosphere comes from fossil-fuel combustion, together with other greenhouse gases (GHGs). However, the stabilization and further reduction of $\mathrm{CO}_{2}$ emissions are not simple tasks, especially for developing nations which will inevitably face many problems when addressing this issue because of their population growth and industrial development.

In this paper, we describe the results of an analysis of long-term global energy strategies under carbon-emission constraints and derive their policy implications. The study has been jointly organized by IIASA and CRIEPI during 1990-1992 with the goal to create a methodological approach for composing energy systems with different levels of $\mathrm{CO}_{2}$-emission constraints, to analyse scenarios of global/regional energy-system development, and to examine possible measures and technologies to control future carbon emissions.

\section{BACKGROUND AND APPROACH}

Two simulation models were applied in the study: the MEDEE-2 model (see, for example, Lapillonne $^{1}$ and Chateau and Lapillonne ${ }^{2}$ ) was used to generate the final energy-demand projections, which were then supplied as inputs to the LEAP model (see Raskin ${ }^{3}$ ) for analyses of two major scenarios, based on different orientations with respect to energy-conservation policy: (A) a dynamics-as-usual scenario with the rates of social, economic, and technological changes worldwide staying the same over the time horizon (with differences by regions) and the competition between fuels and energy forms based primarily on market mechanisms. (B) An 
enhanced efficiency and conservation scenario, for which special measures, in addition to the conditions specified in scenario (A), are applied to promote energy-efficiency improvements in all regions and all economic sectors.

The reference scenario (A) assumes that the social/economic/technological progress in each region will continue at the same average rate of change as observed since the 1970s. For example, the structural changes in national economies are assumed to be rather slow; energy-efficiency improvements of individual processes in industrial production (e.g., steel) are steady and modest; lifestyle indices will follow recent trends, e.g., the ownership of private cars will spread especially in developing countries, and modal shifts to public transportations will be promoted only gradually; slow house retrofitting will take place; trends in energy intensities per value added in national economies are assumed to continue as observed in the past, and changes in the primary energy mix are modest.

On the other hand, in scenario (B) it is assumed that all available efficiency improvements in energy end-uses and reasonable changes in social behavior are implemented, together with noticeable shifts in primary energy supplies.

Three cases for each final energy-demand scenario, representing different paths of primary energy-supply formation, were then defined for further analysis. The three cases for scenario (A) are: (i) The Base Case (A1) with no special constraints assumed on energy-systems development and modest introduction of nuclear energy and renewables. (ii) A Nuclear Moratorium (A2) with a freeze on nuclear energy at the capacity level corresponding to current operations, construction and plans. There will be no new construction but replacements of decommissioned plants are allowed. (iii) In the Supply-Side Measures Case (A3), all available measures for energy efficiency improvements are undertaken.

The three cases for scenario (B) are: (i) the Demand-Side Measures Case (B1) with all available measures in energy-conservation and energy-efficiency improvements undertaken primarily in the energy end-use sectors. (ii) A Nuclear Moratorium (B2), as in case (A2), but with a lower final energy-demand profile. (iii) Accelerated $\mathrm{CO}_{2}$ Abatement (B3) with enhanced energy-systems restructuring on both the supply and the demand sides, as well as $\mathrm{CO}_{2}$ emission reductions to achieve a given goal.

Cases (A1) and (B1) are constrained by fossil-fuel supplies or implicitly by the price competitiveness of fossil fuels and by modest introduction of new energy technologies. Cases (A2) and (B2) involve the constraints of (A1) and (B1), respectively, in addition to the assumption that the nuclear generation capacity will remain unchanged after 2010. For (A3), it is assumed that all available measures are implemented for energy production and conversion, i.e. fuel switching, introduction of new and advanced energy technologies, and enhanced electrification due to expanded utilization of nuclear energy and renewables. For (B3), it is assumed that all possible measures for both end-use and supply efficiencies are exploited. For (B3), we tested the assumption that global carbon emission from energy systems in the year 2050 will be reduced to roughly $40 \%$ of the current level. This reduction target is taken from the Intergovernmental Panel for Climate Change (IPCC) Interim Report, Policymakers Summary of the Scientific Assessment of Climate Change (Report to IPCC from Working Group 1, June 1990) as the reduction level required for stabilizing the atmospheric carbon concentration. Needless to say, it is beyond the scope of our study to discuss if humanity should really pursue this target or the feasibility of its implementation. We simply employed this IPCC target of carbon-emission reduction as a boundary condition in model simulation. The structure of the study is shown in Fig. 1, which illustrates the links and evolutions of scenarios/options analysed.

The final energy-demand projections were investigated for different geographical, geopolitical, and economic characteristics in 10 identified world regions. Here, we focus on the aggregated results and trends in comparing the developed and developing countries. The time horizon of the study is 2050 . 


\begin{tabular}{|c|c|c|c|}
\hline & \multicolumn{3}{|c|}{ Supply-Side Constraints: } \\
\hline & $\begin{array}{l}\text { Nuclear } \\
\text { Moratorium } \\
\text { After } 2000\end{array}$ & $\begin{array}{l}\text { Historical } \\
\text { Evolution }\end{array}$ & $\begin{array}{l}\text { Accelerated } \\
\mathrm{CO}_{2} \text { Abatement }\end{array}$ \\
\hline $\begin{array}{l}\text { Final energy demand scenarios: } \\
\text { Dynamics-as-Usual }\end{array}$ & $(\mathrm{A} 2)$ & $\begin{array}{l}\text { Base Case } \\
\text { (A1) }\end{array}$ & $\begin{array}{l}\text { Supply-side } \\
\text { measures } \\
\text { (A3) }\end{array}$ \\
\hline $\begin{array}{l}\text { Enhanced Efficiency and } \\
\text { Conservation }\end{array}$ & (B2) & $\begin{array}{l}\text { Demand- } \\
\text { side measu- } \\
\text { res (B1) }\end{array}$ & $\begin{array}{l}\text { All available } \\
\text { measures for } \\
\text { realising } 60 \% \\
\text { reduction } \\
\text { (B3) }\end{array}$ \\
\hline
\end{tabular}

Fig. 1. A framework for the case study.

Two major factors govern future energy demand: population growths and economic activity. The UN population projections ${ }^{4}$ were incorporated to the year 2030 and, thereafter (to 2050), our own estimates were applied. The economic activity outlook is based on exogenous projections determined by the Energy Modeling Forum (EMF-12 Working Group, 1990-1991). We made some modifications, mainly for the former socialist countries (U.S.S.R. and Eastern Europe).

\section{LONG-TERM ENERGY PROJECTIONS}

Over the first half of the 21st century, the world primary energy consumption was found to increase from 8.6 gigatons of oil equivalent (Gtoe) in 1990 to 10 Gtoe in 2000 and further to 12-24 Gtoe in 2050, with a reference value of 18.8 Gtoe in case (A1) (Table 1). A nuclear moratorium policy, as assumed in cases (A2) and (B2), may lead to lower levels of total primary energy consumption than in cases with a higher share of nuclear energy because of the conversion efficiencies assumed for nuclear generation and its alternatives, which are considered to be primarily coal-fired power. Case (A3) results in a substantial increase of primary energy supply, up to 24 Gtoe in 2050 , which is one-quarter greater than for (A1), although the final energy-demand profile is the same. This result is found because non-carbon energy carriers, which are characterized by lower efficiencies than fossil fuels, are projected to represent larger fractions of the totals. The same result is observed for case (B3), for which the primary consumption is projected to become $17.2 \mathrm{Gtoe}$ in $2050,40 \%$ higher than for case (B1) at 12.3 Gtoe. Even though the final energy demand [as seen in (B)] will decline, the primary supply will increase

Energy demand in developed countries was evaluated to stay at the current level over the time horizon of the study or may even slightly decline. This result is not surprising since extrapolating recent trends in some developed countries shows that the population will almost stabilize or even decrease and the societies will become more mature. Meanwhile, major portions of the future world-energy demand growth will be justified by the needs of developing countries to reach higher economic activity levels and living standards. It was found that the primary energy demand in developing countries will increase by a factor of 3 to 5 compared with today's level. The share of developing countries in the world primary energy consumption will double from $28 \%$ currently to $55-60 \%$ in 2050 . All these changes mean that within a few decades the burden of the global energy problems will shift from developed countries to developing countries, creating new potential for political tensions on the world energy scene unless proper measures and steps are undertaken now. 
Table 1. Primary energy projections (Mtoe).

\begin{tabular}{|c|c|c|c|c|c|}
\hline Scenario/Region & 1980 & 1990 & 2000 & 2010 & 2050 \\
\hline \multicolumn{6}{|l|}{ Dynamics-as-Usual Scenario } \\
\hline $\begin{array}{l}\text { Base Case }(A 1) \\
\text { Developed countries } \\
\text { Developing countries }\end{array}$ & $\begin{array}{l}7004 \\
5379 \\
1625\end{array}$ & $\begin{array}{l}8580 \\
6196 \\
2384\end{array}$ & $\begin{array}{r}10,055 \\
6910 \\
3145\end{array}$ & $\begin{array}{r}12,015 \\
7385 \\
4630\end{array}$ & $\begin{array}{r}18,795 \\
8715 \\
10,080\end{array}$ \\
\hline $\begin{array}{l}\text { Nuclear Moratorium Case }(A 2) \\
\text { Developed countries } \\
\text { Developing countries }\end{array}$ & $\begin{array}{l}7004 \\
5379 \\
1625\end{array}$ & $\begin{array}{l}8580 \\
6196 \\
2384\end{array}$ & $\begin{array}{r}10,055 \\
6910 \\
3145\end{array}$ & $\begin{array}{r}12,060 \\
7340 \\
4720\end{array}$ & $\begin{array}{r}18,995 \\
8570 \\
10,425\end{array}$ \\
\hline $\begin{array}{l}\text { Supply-side Measures Case (A3) } \\
\text { Developed Countries } \\
\text { Developing countries }\end{array}$ & $\begin{array}{l}7004 \\
5379 \\
1625\end{array}$ & $\begin{array}{l}8580 \\
6196 \\
2384\end{array}$ & $\begin{array}{c}10,025 \\
6880 \\
3145\end{array}$ & $\begin{array}{r}12,675 \\
7885 \\
4790\end{array}$ & $\begin{array}{l}24,025 \\
11,915 \\
12,110\end{array}$ \\
\hline \multicolumn{6}{|l|}{$\begin{array}{l}\text { Enhanced Efficiency and } \\
\text { Conservation Scenario }\end{array}$} \\
\hline $\begin{array}{l}\text { Demand-side Measures Case }(B 1) \\
\text { Developed countries } \\
\text { Developing countries }\end{array}$ & $\begin{array}{l}7004 \\
5379 \\
1625\end{array}$ & $\begin{array}{l}8580 \\
6196 \\
2384\end{array}$ & $\begin{array}{l}9825 \\
6680 \\
3145\end{array}$ & $\begin{array}{r}10,490 \\
6475 \\
4015\end{array}$ & $\begin{array}{r}12,325 \\
5245 \\
7080\end{array}$ \\
\hline $\begin{array}{l}\text { Nuclear Moratorium Case (B2) } \\
\text { Developed countries } \\
\text { Developing countries }\end{array}$ & $\begin{array}{l}7004 \\
5379 \\
1625\end{array}$ & $\begin{array}{l}8580 \\
6196 \\
2384\end{array}$ & $\begin{array}{l}9825 \\
6680 \\
3145\end{array}$ & $\begin{array}{r}10,385 \\
6385 \\
4000\end{array}$ & $\begin{array}{r}12,105 \\
5095 \\
7010\end{array}$ \\
\hline $\begin{array}{l}\text { Accelerated } \mathrm{CO}_{2} \text { Abatement Case (B3) } \\
\text { Developed countries } \\
\text { Developing countries }\end{array}$ & $\begin{array}{l}7004 \\
5379 \\
1625\end{array}$ & $\begin{array}{l}8580 \\
6196 \\
2384\end{array}$ & $\begin{array}{l}9825 \\
6680 \\
3145\end{array}$ & $\begin{array}{r}10,760 \\
6660 \\
4100\end{array}$ & $\begin{array}{r}17,185 \\
7145 \\
10,040\end{array}$ \\
\hline
\end{tabular}

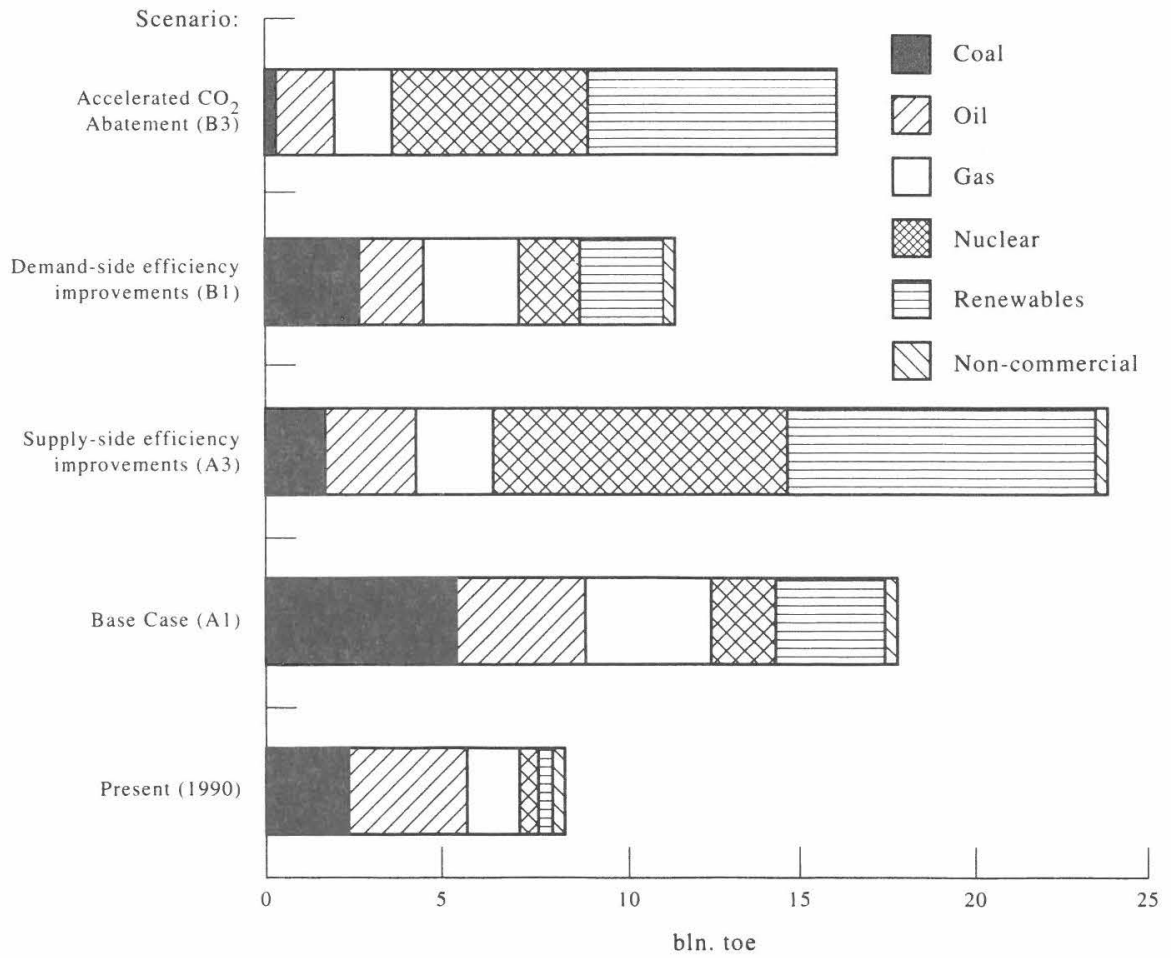

Fig. 2. World primary energy production in 2050 for various scenarios. 
The world primary energy mix will depend heavily on development paths chosen over the next decades, as seen in Fig. 2. In 1990, the production of the fossil fuels (coal, oil, and natural gas) is evaluated at $7.2 \mathrm{Gtoe}$, which corresponds to $84 \%$ of the total primary consumption. In case (A1), this amount will increase in the year 2050 up to 13.5 Gtoe, although with a declining share of $72 \%$ in the total primary consumption of $18.8 \mathrm{Gtoe}$. Case (A2) will result in increases of coal consumption up to $7 \mathrm{Gtoe}, 27 \%$ more than in the Base Case. In case (B3) with stringent constraints on $\mathrm{CO}_{2}$ emissions, the consumption of fossil fuel must be reduced to $4.1 \mathrm{Gtoe}, 25 \%$ of the total $17.2 \mathrm{Gtoe}$ in 2050 ; nuclear $(6.3 \mathrm{Gtoe}, 36 \%)$ and renewables $(6.9 \mathrm{Btoe}, 40 \%)$ will reach even larger shares than fossils in the primary supply.

Electricity maintains its position as the most universally useful energy carrier in all sectors of end-use, including transportation. The environmental protection goals can be achieved most effectively with applications of electricity-driven technologies. Economic and social developments, as well as improvements in living standards in developing nations, are impossible without electrification. Therefore, growth of electricity generation is projected in both developed and developing countries. Total electricity generation will increase from about 11 terawatt-hours (TWh) in 1990 to $14-14.5$ TWh in 2000 and further to $40-45$ TWh in 2050 . The developing countries, which now generate about $19 \%$ of the world's electricity, will increase their share to $50-60 \%$ in the long term.

The future of nuclear energy remains one of the most controversial points in all energy projections. Nuclear energy is expected to play one of the key roles in Case (B3), with drastic expansion of generation capacities. However, even the far less magnificent expansion of nuclear utilization projected in the Base Case (A1) may involve many difficulties. Prospects for this energy source over the next couple of decades are quite uncertain. On the one hand, risk and safety issues make nuclear energy less accepted in many developed countries. On the other hand, the idea that environmental degradations could be prevented by replacing fossil fuels, especially coal, by nuclear energy is receiving an increasing support. To achieve the Base Case, the maximum construction capability of the current nuclear industries must be maintained for many years. Thus, it will be extremely difficult to realize the Accelerated Abatement Case unless a comprehensive revitalization of the world's nuclear industry, possibly with new concepts for advanced nuclear reactor systems, is accomplished.

For renewable energy sources, low energy densities and large daily and seasonal fluctuations of outputs make their material intensities larger than those of conventional fossil fuels or nuclear energy. Moreover, many renewables may require backup power supplies and storage devices, which aggravate the situation. Considering these aspects and especially costs only limited applications of renewables appear promising for the next several decades. Renewable energy utilization will be pursued primarily in remote and rural regions with decentralized, inefficient energy systems, where it will replace direct combustion of expensive liquid fuels and unsustainable use of fuelwood. Although construction electricity-supply grids in less developed regions will require huge investments, electricity supply is a key infrastructure for industrial development and social progress. This path, exploitation of decentralized electricity-supply systems with renewable sources, is an indispensable step with few alternatives. Developed nations should take active steps to implement effective financial and institutional arrangements to encourage developing countries to go forward. In summary, a drastic restructuring to an advanced energy system with non-carbon resources as major energy supplies will be indispensable in realizing a substantial emission abatement while meeting increasing energy demands.

\section{$\mathrm{CO}_{2}$ EMISSION}

The study shows that global annual $\mathrm{CO}_{2}$ emissions will increase to 2010 from 6.3 gigatons of carbon (Gt-C) today to $6.7-8.8 \mathrm{Gt}-\mathrm{C}$ in 2010 , and will then vary significantly, depending on the assumed scenario (see Fig. 3). 


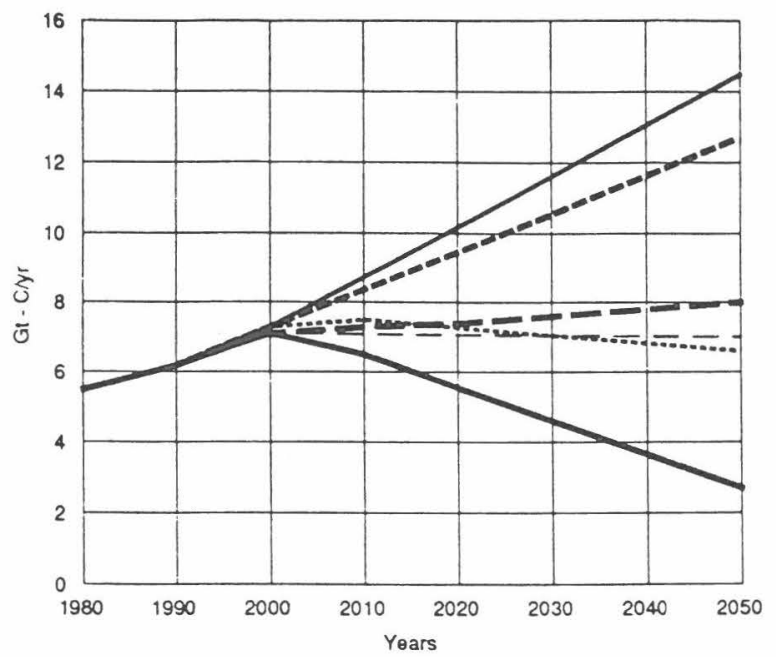

Scenario:

Dynamics-as-Usual

Base Case (A1)

$\longrightarrow$

Nuclear Moratorium (A2)

Suppy-side Measures (A3)

-

Enhanced Conservation

Demand-side Measures (B1)

Nuclear Moratorium (B2)

$\Leftrightarrow \infty$

Accelerated $\mathrm{CO}_{2}$ Abatement (B3)

Fig. 3. $\mathrm{CO}_{2}$ emissions by global energy systems.

It is generally difficult or impossible to separate explicitly the effectiveness of supply-side and demand-side measures in analyses using macroscopic models like ours. We find that demand-side measures, such as conservation efforts and adoption of efficient equipment by end-users, can play a useful role in controlling global carbon emissions in the short term, e.g., to 2010, although the effectiveness of these may not be further improved, i.e. emission in case (B1) cannot be substantially reduced after 2010. Meanwhile, supply-side measures, such as large-scale development and utilization of nuclear energy and enhanced introduction of renewable energy sources, will require a couple of decades for demonstration of strong abatement potential. The approach to be undertaken for carbon-emission control should therefore involve steps to promote $R \& D$ of advanced supply technologies starting today, while carrying out enhanced conservations and efficiency improvements in the near term.

The influence of a nuclear moratorium varies depending on the final demand scenarios. In case (A2), carbon emission in 2050 is $14.5 \mathrm{Gt}-\mathrm{C}$ per year, which is $15 \%$ higher than for Base Case (A1); case (B2) at $8.0 \mathrm{Gt}-\mathrm{C}$ per year shows an $11 \%$ increase over case (B1) at $7.0 \mathrm{Gt}-\mathrm{C}$ per year. The enhanced conservation and efficiency improvements in scenario (B) are expected to mitigate the impacts a nuclear moratorium is imposed, compared with the other nuclear moratorium case in scenario (A). The overall impacts on the carbon-emission increase with a nuclear moratorium are, however, substantial.

\section{POLICY IMPLICATIONS OF THE ENERGY/CO 2 SCENARIOS}

\section{Long-term structural transitions of carbon emission abatements}

According to Kaya, ${ }^{5} \mathrm{CO}_{2}$ emissions may be expressed as

$$
\mathrm{CO}_{2}=\left(\mathrm{CO}_{2} / \text { energy }\right) \times(\text { energy } / \mathrm{GNP}) \times \mathrm{GNP} X \times Y \times \mathrm{GNP} .
$$

Also,

$$
\mathrm{d}\left(\mathrm{CO}_{2}\right) / \mathrm{CO}_{2}=\mathrm{d} X / X+\mathrm{d} Y / Y+\mathrm{d}(\mathrm{GNP}) / \mathrm{GNP} .
$$

Nakićenovic ${ }^{6}$ showed that the primary energy intensity, including non-commercial biomass at constant GDP, has declined at an average rate of $1 \%$ per year; however, these improvements accelerated to $2-3 \%$ per year after the early 1970s. Yamaji et $\mathrm{al}^{7}$ have analysed the changes of $X$ and $Y$ by country after the first oil crisis. They observed that most of the developed countries 

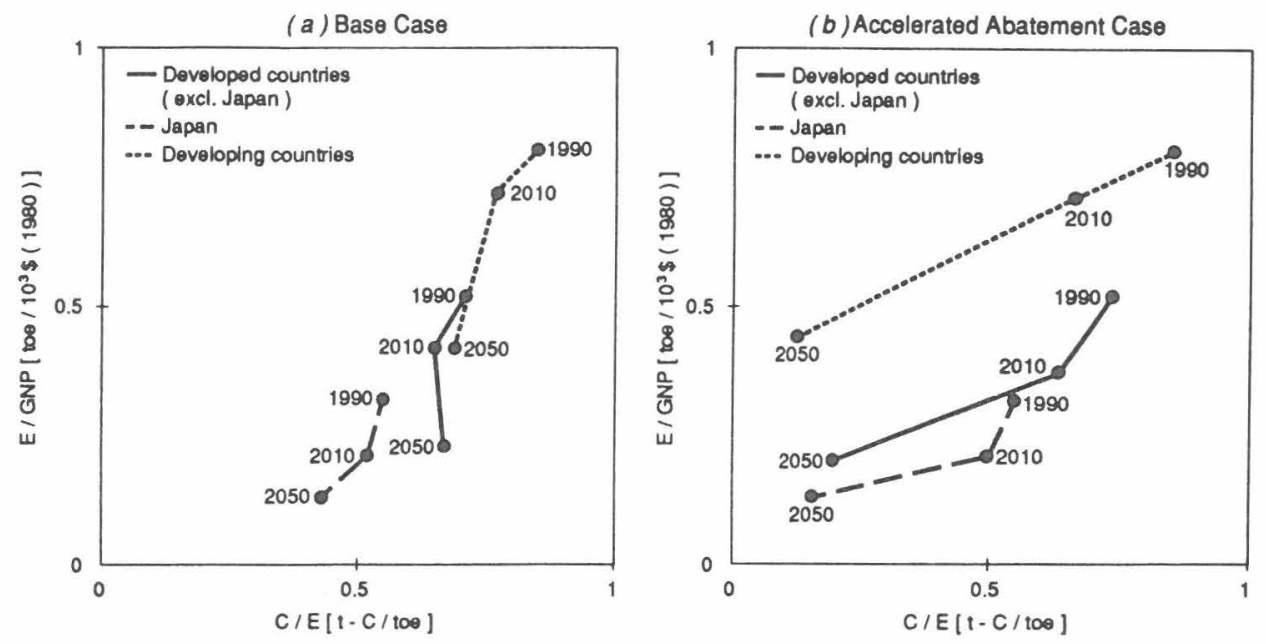

Fig. 4. Dynamics in long-term structural changes.

have improved both indices from 1 to $2 \%$ annually with the notable exceptions of Japan, where the improvement of energy intensity was $3 \%$ per year, and France and Sweden, both of which reduced the carbon intensity by about $3 \%$ per year (both countries have benefited from rapid restructuring of the energy supply through intensive development and utilization of nuclear energy).

Figure 4 shows $X$ and $Y$ for case (A1) and (B3), for the periods 1990-2010 and 2010-2050. In case (A1), the global energy intensity is reduced roughly $1 \%$ per year from 2010 to 2050 , with the exception of the developing region where it may increase over the short term to 2010 because of economic development. At the same time, the annual average worldwide improvement rate in carbon intensity is only $0.1 \% / \mathrm{yr}$. This result shows that energyconservation and efficiency improvements are the most useful measures for achieving global carbon-emission control.

In order to promote maximum global carbon-emission reductions, it is necessary to increase the rates of both energy-efficiency improvements and decarbonization of energy systems. In case (B3), the remarkable de-carbonization is implemented worldwide by as much as $3 \%$ per year to the year 2050. Although energy conservation should be promoted as well, the improvement rate remains roughly $1 \%$ per year. To achieve this goal in global decarbonization, the developing region must improve its carbon intensity even faster than the developed region. Obviously, this cannot be achieved by the developing region alone. Thus, the developed region must recognize the need to participate much more actively in economic and social developments, as well as in efforts to abate carbon emission, in the developing region.

\section{Viewpoints on equity}

Tables 2 and 3 list the per capita indices for cases (A1) and (B3). According to Marland et $\mathrm{al},{ }^{8}$ the per capita carbon emission in the year 1986 varies from country to country, with the highest being roughly five tons per capita in the U.S.A. and the lowest in some developing countries as much as 10 times lower than in the U.S.A.

Fujiii ${ }^{9}$ has analysed the increase of observed atmospheric carbon content over many years and has concluded that the developed countries have contributed more to the global carbon concentrations than corresponds to their current share in the global emission. He extended the analysis to future emission quotas. The results show that even though the savings on carbon emissions in the developing countries in the past may have been offset by an explosive increase 
Table 2. Equity obstacles for global cooperation for the Base Case (A1).

\begin{tabular}{lccccc}
\hline & 1990 & $1990-2010$ & 2010 & $2010-2050$ & 2050 \\
\hline C/capita & $(t$-C/person $)$ & $(\% / y r)$ & $(t$-C/person $)$ & $(\% / y r)$ & $(t-C /$ person $)$ \\
$\quad$ Total & 1.19 & -0.06 & 1.17 & -0.02 & 1.16 \\
Developed & 3.46 & 0.04 & 3.49 & 0.21 & 3.80 \\
Japan & 2.01 & -0.02 & 2.00 & -0.48 & 1.65 \\
Developing & 0.49 & 1.14 & 0.62 & 0.44 & 0.74 \\
Developed/Developing & $\approx 7.00$ & & $\approx 6.00$ & & $\approx 5.00$ \\
& & & & & $(\% / y r)$ \\
E/capita & $($ toe/person $)$ & $(\% / y r)$ & $($ toe $/$ person $)$ & 0.07 & 1.73 \\
Total & 1.62 & 0.20 & 1.68 & 0.16 & 5.61 \\
Developed & 4.88 & 0.37 & 5.25 & 0.03 & 3.97 \\
Japan & 3.79 & 0.18 & 3.92 & 0.73 & 1.09 \\
Developing & 0.59 & 1.57 & 0.81 & & $\approx 5.00$ \\
Developed/Developing & $\approx 8.00$ & & $\approx 6.50$ & &
\end{tabular}

of future populations, they may claim for, at least, the same level of emissions as the developed countries.

As shown in the tables, the current discrepancy of per capita carbon emission between the developed and developing regions is estimated to be a factor of seven. If the developed regions reduced their per capita emissions to the level of the developing region, the average world level would be $60 \%$ lower than the current level and, consequently, would fulfill the target for total global emission. This discrepancy, however, does not disappear before the year 2050 in either the Base Case (A1) or case (B3): it is five times in the former case and six times in the latter, although the absolute levels are different. On the other hand, the per capita primary energy consumption, which shows a discrepancy of eight times at present, will become five and four times in 2050, respectively, showing that the changes in energy systems will proceed more slowly than the expansion of energy demand.

Even though the inequality of energy consumption assumes more improvement in case (B3) than in the Base Case (A1), the inequality in carbon emission appears to get worse. Since this phenomenon results from an enhanced supply of clean non-carbon energy in the developing region in the Accelerated Abatement Case, possibly with technology transfer from the developed countries, this fact should not be treated as an unfavorable outcome for the developing region. Here we note, however, that the difficulty of leading all countries to a reasonably equitable level at a given time remains an impossible obstacle.

Although the main stage of society's fight against global warming will shift to the developing region in the early 21 st century, the main actors will remain in the developed countries. To

Table 3. Equity obstacles for global cooperation for the Accelerated Abatement Case (B3).

\begin{tabular}{lccccc}
\hline & 1990 & $1990-2010$ & 2010 & $2010-2050$ & 2050 \\
\hline C/capita & $(t-$ C/person $)$ & $(\% / y r)$ & $(t$-C/person $)$ & $(\% / y r)$ & $(t$-C/person $)$ \\
Total & 1.19 & -1.24 & 0.92 & -3.25 & 0.25 \\
Developed & 3.46 & -0.84 & 2.92 & -2.94 & $0 \cdot 88$ \\
Japan & 2.01 & -0.42 & $1 \cdot 85$ & -3.23 & 0.50 \\
Developing & 0.49 & -0.54 & $0 \cdot 44$ & -2.80 & $0 \cdot 14$ \\
Developed/Developing & $\approx 7.00$ & & $\approx 7 \cdot 00$ & & $\approx 6.00$ \\
& & & & & \\
E/capita & $($ toe/person $)$ & $(\% / y r)$ & $($ toe/person $)$ & $(\% / y r)$ & $($ toe/person $)$ \\
Total & 1.62 & -0.18 & 1.56 & 0.03 & 1.58 \\
Developed & 4.88 & -0.17 & 4.71 & -0.07 & 4.58 \\
Japan & 3.79 & -0.07 & 3.73 & -0.24 & 3.39 \\
Developing & 0.59 & 1.42 & 0.79 & 0.79 & 1.08 \\
Developed/Developing & $\approx 8.00$ & & $\approx 6.00$ & & $\approx 4.00$ \\
\hline
\end{tabular}


implement a global development strategy, it will be of crucial importance to establish an appropriate institutional scheme to enable smooth transfer of technologies and financial resources from the developed nations to the developing nations, as well as to encourage the developing countries to participate in international negotiations and agreements.

\section{CONCLUDING REMARKS}

We have presented a simulation analysis based on scenario assumptions, among which a $60 \%$ reduction of carbon emissions worldwide was chosen as a boundary condition. It is commonly considered that even if this radical carbon-abatement target for energy systems is met, the carbon concentration in the atmosphere will continue to increase at least to 2050. Thus, global warming may proceed to a certain level in any case. For this reason, parallel efforts in other spheres of human activities are also needed, e.g., preventing deforestation and restoring damaged forests, especially in tropical zones, and reducing other GHG emissions which contribute not less than $50 \%$ to the overall global warming.

Our analysis is a rough outline for various evolutions of global energy systems to 2050 . Further verifications of scenarios are needed, especially for techno-economic and sociobehavioral realities. Special attention should be given to uncertainties about global warming. Cost-benefit analyses of short- and long-term measures to prevent, mitigate or adapt to climatic changes will be especially important in finding a common approach to the most favorable and acceptable global strategies.

Progress in the developing countries will determine the future world-energy profile and global environmental pollution. Therefore, future global energy studies should be focused on the energy supply and demand of this region with special emphasis on social, economic and technological aspects of development. Effective institutional arrangements are needed to encourage the collaboration of developing countries on long-term global environmental problems.

Acknowledgements-Valuable comments and suggestions on energy demand and supply projections were received from J. Marecki (Technical University of Gdansk, Poland), W. Riesner (Technische Hochschule Zittau, Germany), and L. Schipper (Lawrence Berkeley Laboratory, U.S.A.). We are grateful to J. A. Edmonds (Battelle Pacific Northwest Laboratory, U.S.A.), L. Hamilton (Brookhaven National Laboratories, U.S.A.), and J.-R. Frisch (Electricité de France) for their constructive and critical remarks on the study. The discussions of some aspects with B. Doos, N. Nakićenović, A. Grübler, L. Schrattenholzer, and others at IIASA were very productive. We extend our appreciation to K. Yamaji (CRIEPI) for his initiative in launching this study and his careful supervision over the past two years. All responsibilities for the contents and possible errors are the authors alone.

\section{REFERENCES}

1. B. Lapillonne, "MEDEE-2: A Model for Long-Term Energy Demand Evaluations," RR-78-17, IIASA, Laxenburg, Austria (1978).

2. B. Chateau and B. Lapillonne, Energy Demand: Facts and Trends, Springer, Vienna (1980).

3. P. Raskin, "LEAP: A Description of the LDC Energy Alternative Planning System," Beijer Institute/Scandinavian Institute of African Studies, Uppsala, Sweden (1986).

4. United Nations, "World Population Prospects," Population Studies No. 106, New York, NY (1989).

5. Y. Kaya, paper presented at the EIS/RSWG/IPCC Meeting, Geneva (May 1989).

6. N. Nakićenović, "Energy Strategies for Mitigating Global Change," Working Paper WP-92-1, IIASA, Laxenburg, Austria (1992).

7. K. Yamaji, R. Matsuhashi, Y. Nagata, and Y. Kaya, "An Integrated System for $\mathrm{CO}_{2} /$ Energy/GNP Analysis: Case Studies on Economic Measures for $\mathrm{CO}_{2}$ Reduction in Japan," paper presented at the Workshop on Economic/Energy/Environmental Modeling for Climate Policy Analysis, Washington, DC (1990). 
8. G. Marland, T. A. Boden, R. G. Griffin, S. F. Huang, P. Kanciruk, and T. K. Nelson, "Estimates of $\mathrm{CO}_{2}$ Emissions from Fossil Fuel Burning and Cement Manufacturing, Based on the United Nations Energy Statistics and the U.S. Bureau of Mines Cement Manufacturing Data," ORNL/CDIAC-25 (NDP-030), Oak Ridge National Laboratory, Oak Ridge, TN (1989).

9. Y. Fujii, "An Assessment of the Responsibility for the Increase in the $\mathrm{CO}_{2}$ Concentration and Inter-generational Carbon Accounts," Working Paper WP-90-55, IIASA, Laxenburg, Austria (1990). 
